\title{
Anaplastic astrocytoma mimicking progressive multifocal leucoencephalopathy: a case report and review of the overlapping syndromes
}

\author{
Ema Kantorová ${ }^{*}$, Michal Bittšanský2 ${ }^{2}$ Štefan Sivák', Eva Baranovičová2, Petra Hnilicováa , Vladimír Nosál', \\ Daniel Čierny ${ }^{2}$, Kamil Zeleňák ${ }^{3}$, Wolfgang Brück ${ }^{4}$ and Egon Kurča ${ }^{1}$
}

\begin{abstract}
Background: Co-occurrence of multiple sclerosis (MS) and glial tumours (GT) is uncommon although occasionally reported in medical literature. Interpreting the overlapping radiologic and clinical characteristics of glial tumours, MS lesions, and progressive multifocal leukoencephalopathy (PML) can be a significant diagnostic challenge.

Case presentation: We report a case of anaplastic astrocytoma mimicking PML in a 27-year-old patient with a 15-year history of MS. She was treated with interferon, natalizumab and finally fingolimod due to active MS. Follow-up MRI, blood and cerebrospinal fluid examinations, and biopsy were conducted, but only the latter was able to reveal the cause of progressive worsening of patient's disease.

Conclusions: Anaplastic astrocytoma misdiagnosed as PML has not yet been described. We suppose that the astrocytoma could have evolved from a low grade glioma to anaplastic astrocytoma over time, as the tumour developed adjacent to typical MS plaques. The role of the immunomodulatory treatment as well as other immunological factors in the malignant transformation can only be hypothesised. We discuss clinical, laboratory and diagnostic aspects of a malignant GT, MS lesions and PML. The diagnosis of malignant GT must be kept in mind when an atypical lesion develops in a patient with MS.
\end{abstract}

Keywords: Anaplastic astrocytoma, Multiple sclerosis, Tumefactive lesion, Progressive multifocal leukoencephalopathy, Immune reconstitution syndrome

\section{Background}

Multiple sclerosis (MS) is a disabling inflammatory demyelinating disease of the central nervous system (CNS). Early initiation of immunotherapy and its adjustment in view of ongoing inflammatory disease activity is desirable [1]. The main treatment goals aim at terminating inflammation and at reducing axonal damage [1]. Establishing MS diagnosis and decisions about the initial and ongoing treatments should not be made until other disorders that could better explain neurological symptoms and signs are excluded [1]. Although glial brain tumors (GT) have occasionally been

\footnotetext{
* Correspondence: kantorova@jfmed.uniba.sk

${ }^{1}$ Clinic of Neurology, Jessenius Faculty of Medicine, Comenius University in Bratislava, Kollárova 2, 03659 Martin, Slovak Republic

Full list of author information is available at the end of the article
}

reported in patients with MS, with only about 80 cases described in medical literature so far [2-5], this cooccurrence is uncommon since MS is caused by putative CNS autoimmune mechanisms whereas brain neoplasms may depended on a subclinical immunosuppressive state [6]. However, the last 15 years have seen increased use of immunomodulatory therapies (IMT) for relapsing MS, and considerable progress in the development of new, much stronger IMT for MS [7]. That rises questions about longterm safety of IMT as well as their risks and benefits [7]. Currently we know that several IMT make patients more susceptible to developing dangerous brain infection caused by John Cunningham virus (JCV) called progressive multifocal leukoencephalopathy (PML) [8-12]. However, MRI findings of tumefactive demyelinating lesions (TDL), PML 
and GT can overlap [12-19]. The first appearance of atypical brain lesion in an MS patient should lead to more extensive investigation in order to exclude another disease [15-19]. However, in some cases only biopsy is capable to reveal the cause of atypical MRI lesion [20,21].

Here we describe the case of a malignant GT in a patient with early onset of MS. To the best of our knowledge, anaplastic astrocytoma misdiagnosed as PML has not yet been described. We discuss diagnostic tools that can help in differential diagnosis.

\section{Case presentation}

Here we report on a 27-year-old woman with the first neurological symptoms suggesting MS in 1999 at the age of 12 . Her medical and psychosocial history was negative, but her family history was positive. Patient's father is also treated for MS. The patient's clinical timeline follows (Figs. 1, 2, 3, 4, 5, 6 and 7):

\section{Discussion and conclusions}

Our case shows that MS can have variable presentation therefore concurrence of MS with brain tumours may remain undetected for some time. One possible explanation is that an association of MS with overall risk of cancer has not been proved [22, 23]. One meta-analysis even identified a small but significant reductions of total cancer risk in patients with MS (odds ratio [OR] 0.92; 95\% CI 0.87-0.97, $p=0.004)$ [24]. Another meta-analysis suggested lower overall co-occurrence of cancer in patients with MS [24]. On the other hand, a recent large systematic study evaluating risk and survival of brain tumours among patients with autoimmune disorders found higher standardised incidence of brain tumours in MS (OR 2.14; 95\% CI 1.65-2,73) than in other autoimmunity disorders of the CNS [25]. The most frequent brain tumours were gliomas with OR 1.49; 95\% CI 0.91-2.31. In this study, the risk of glioma-associated deaths in MS patients was relatively high (OR 2.3; 95\% CI

\section{A 12-year-old girl with negative medical history presents with vestibular syndrome lasting three weeks \\ 1999-2006 After having experienced several relapses with various symptoms (paresthesias of her left and right upper limbs, paresthesias of her distal limbs, weakness of upper limbs), she fulfilled McDonald criteria for definite relapsing-remitting MS due to demyelinating lesions in MRI (Fig. 1a, b, c), positive oligoclonal bands type 2 in cerebrospinal fluid (CSF) and positive visual evoked potentials (VEP). \\ 2006 Several rounds of intravenous boluses of methylprednisolon were effective and the patient improved. When she started treatment by October interferon beta la (Rebif ${ }^{\oplus}$ Merck-Serono), her Expanded Disability Status Scale (EDSS) was 2.0.}

2008-2009 The treatment was interrupted due to her pregnancy in February 2008. In January 2009 she gave birth. During the early postpartum period the patient's neurological status was unstable.

2009 January The patient suffered three relapses (sensitive symptoms, left-sided hemiparesis, paraparesis of distal limbs) and her EDSS increased to to April $\quad 4.0$ although she obtained several rounds of intravenous methylprednisolon.

2009 May She resumed interferon beta la (Rebif ${ }^{\circledast}$ Merck-Serono) and reached remission.

2011 March Her disease progressed again, her EDSS increased to 4.5 and follow-up MRI reflected clinical activity (Fig. 2a, b). Central quadruparesis to May was more pronounced in her left limbs and spinal ataxia varied over time between a need of assistance when walking longer distances and mild deficit. She responded well to intravenous methylprednisolon rounds.

2012 August To stop the disease progression, she was indicated to natalizumab (Tysabri ${ }^{\circledR}$ Biogen Idec), receiving 12 infusions (august 2012 - september 2013 ).

2013 The follow-up brain 3.0 Tesla MRI showed enlargement of the lesion in the right frontal lobe, evaluated by radiologists as PML

September (Fig. 3a, b, c, d). We also noticed seroconversion of JCV antibodies, but JCV index was low (0.38) and CSF PCR of DNA revealed no copies of JCV (Focus diagnostics, CYPRESS, California, USA).

$2013 \quad$ Not meeting Slovak indication criteria, the patient ceased taking natalizumab. The patient started treatment with fingolimod (Gilenya ${ }^{\circledR}$

December Novartis Pharmaceuticals UK). At that time she was quadruparetic, more prominent on the left side. She needed assistance due to wide-based gait and she had intermittent headaches (mild to moderate congestive-dull or pulsating headache located in bi-temporal areas, partially alleviated by analgesics) EDSS was 5.0.

2014 A follow-up 3.0 Tesla MRI of the brain showed enlargement of the prior frontal lobe lesion (Fig. 4a, b, c), misinterpreted as PML again.

February A new CSF examination showed normal proteinorhachia $(0.22 \mathrm{~g} / \mathrm{l})$ and cellularity (1lymphocyte), not increased lactate (1.91 mmol/l), positive oligoclonal bands type 2 (14 bands), and increased lgG index 1.44. The PCR test of DNA JCV was negative again (0 copies UNILABS, Denmark). We decided to continue with fingolimod.

$2014 \quad$ Over the following several months she developed new clinical symptoms: headache, sporadic epileptic seizures, disorientation. December Immunomodulatory treatment was stopped. Repeated MRI was comparable with the MRI from February 2014, the atypical lesion in the right frontal lobe was in mild progression.

2015 May $\quad{ }^{1} \mathrm{H}$-magnetic resonance spectroscopy ( ${ }^{1} \mathrm{H}-\mathrm{MRS}$ ) detected decreased creatin to cholin ratio in several small areas of the frontal lobe, possibly suggesting tumorous mass (Fig. 5) Brain biopsy of the tumefactive lesion from the right frontal lobe. Histopathological findings revealed presence of anaplastic astrocytoma (Fig. 6a, b, c, d, e)

2015 June The patient needed anti-oedematous (dexamethason or methylprednisolon, boluses of manitol) and anti-epileptic therapy (valproic acid and levetiracetam) due to repeated secondary generalized epileptic seizures and intracranial hypertension syndrome.

2015 August Before starting oncological treatment, 11 methyl-methionine positron emission tomography ( ${ }^{11} \mathrm{C}$ MET PET) showed cortical localization of the brain tumor (Fig. 7). Patient's condition remained unstable due to frequent epileptic seizures. Three weeks later she suddenly died during status epilepticus (23/Aug/2015). 
1.47-3.61). In addition, the data on survival showed the same decrease for both benign and malignant types of tumours co-occurring with MS [25]. Curiously, MS was the only autoimmune disease for which the overall brain cancer and especially glioma-specific survival appeared to decrease in recent years [25]. One explanation could be that comorbidity weakens patient's physical condition. Moreover in MS, glial tumours interfere with mortality burden due to reduced treatment options and lower capacity of the affected brain to resist tumour growth. Another explanation could be that brain tumours remain hidden in demyelinated brain tissue and therefore they are diagnosed later, in advanced stages, which was also our case.

At the beginning of our patient's disease the pathological lesion was connected to the frontal pole of lateral ventricle stretching to the periphery dispersing into the white matter. It was T2- and FLAIR- hyperintense and its localisation near the ventricle favoured TDL over GT (Fig. 1b,c). MRI of the atypical lesion fulfilled the reported characteristics of TDL [15-18]. However, MRI signs of TDL and GT can overlap easily [15, 17, 18]. Brain CT examination may be helpful in differentiation between the TDL and malignant GT [26] but we did not perform it in the early stage. Later, growth activity of the atypical lesion in the frontal lobe, good response to steroids, and absence of clinical signs suggesting tumour [15-18] led to treatment escalation. The effect of natalizumab and fingolimod to the lesion growth was evident and its MRI characteristics evoked suspicion of PML [11-13]. Although CSF examination of DNA JCV is a reliable test of PML, there were also reported cases of PML in JCV-PCR CSF negative patients in early PML as well as during Immune Reconstitution Inflammatory Syndrome (IRIS) [27].

In our patient, minimal mass effect and absence of post-contrast enhancement supported PML diagnosis
[11-13]. Double Inversion Recovery (DIR) (Fig. 4c) confirmed cortical involvement but did not add new information. Cortical lesions are typical for advanced forms of MS but they can be found in PML as well as GT [11-13, 17-20]. Diffusion Weighted Imaging (DWI) hyperintensities (Fig. 3d) favoured PML [11-13]. ${ }^{1} \mathrm{H}-\mathrm{MRS}$ revealed decreased creatine to choline ratio in several areas of the lesion. We did not find changes of glutamate and glutamine peaks, as was reported by Yamashita [14]. ${ }^{1} \mathrm{H}-\mathrm{MRS}$ is able to identify brain tumours or demyelination [11, 28-31] although several authors recommend caution when interpreting ${ }^{1} \mathrm{H}-$ MRS measured concentrations of metabolites in isolation $[11,31]$. As our lesion was not well defined its precise place was estimated. Its localisation and size was finally revealed by ${ }^{11} \mathrm{C}$ MET PET. Increased uptake of ${ }^{11} \mathrm{C}-\mathrm{MET}$, i.e. high proliferation index of ${ }^{11} \mathrm{C}-\mathrm{MET}$ indicating malignancy [32], was found in the right cortical frontal area. Slightly increased uptake of ${ }^{11} \mathrm{C}-\mathrm{MET}$ was also found in left frontal and occipital cortex.

Cortical clinical symptoms, including disorientation, confusion, epileptic seizures, behavioural changes and headaches appeared in our patient in terminal stages of GT progression. They can also be found in patients with PML [8-11]. Moreover, symptomatic seizures correlate with cortical demyelination in advanced forms of MS [33], and could be associated with TDL $[15,16]$.

Basic CSF examination in our patient showed normal proteinorhachia and cell count, but increased number of oligoclonal bands type 2 (14 bands) and IgG index 1.44. These findings suggest active demyelinating processes associated with MS [15, 34] or PML-IRIS [10, 11]. This reaction is unusual in GT, where increased lactate in CSF and hyperproteinorrhachia would be expected [6]. However, we did not prove it.

Retrospective analysis of the blood cellular immunity over the years showed chronic increase of $\mathrm{CD} 4+(50-$
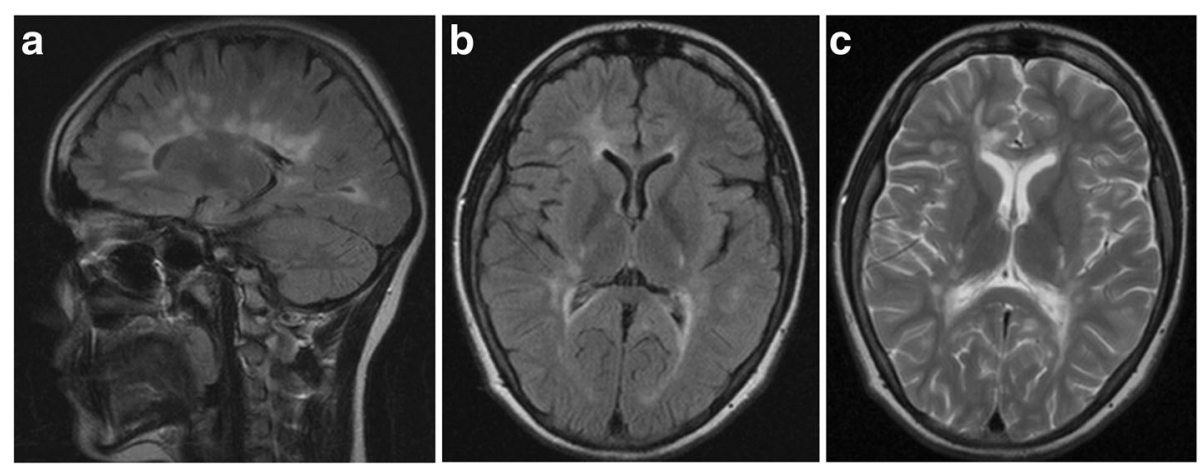

Fig. 1 a FLAIR, Fluid-Attenuated Inversion Recovery, sagittal (2006): Periventricular high-signal intensity lesions exhibiting distribution of ovoid demyelinated periventricular lesions radially oriented to ventricles, which is typical for multiple sclerosis. b FLAIR, Fluid-Attenuated Inversion Recovery, transverse (2006): Atypical tumefactive periventricular demyelinated lesion connected to the frontal pole of the lateral ventricle. c T2w, T2-weighted MRI, transeverse (2006): Atypical hyperintensive tumefactive periventricular demyelinated lesion connected to the frontal pole of the lateral ventricle 

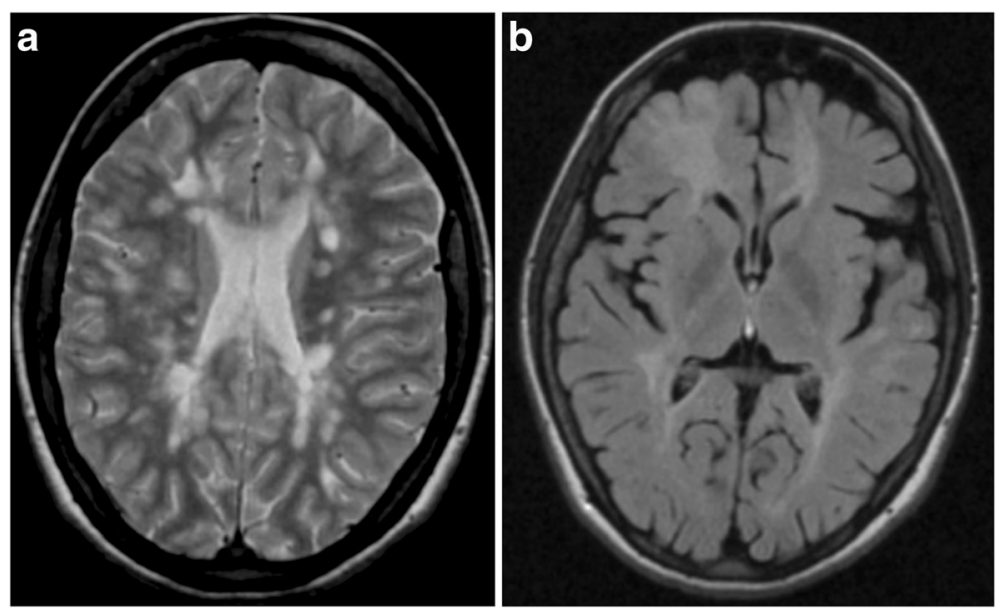

Fig. 2 a Dual Fast SE, Dual Fast Spin-Echo, transverse (2011): Enlargement of the atypical hyperintensive tumefactive demyelinated lesion in the right frontal lobe. b FLAIR, Fluid -Attenuated Inversion Recovery, transverse (2011): Enlargement of the atypical tumefactive demyelinated lesion in the right frontal lobe

$66 \%)$ and mild deficit of CD8 (11-12\% with higher CD4/8 index (4.5-5.0) at the beginning of her disease (20072009). During interferon beta I treatment, CD4+ (55\%) and CD8 (10\%) remained unchanged, while CD16 + CD56 Natural Killers (NK) (4\%, 66 abs) fell, and CD19 rose (31\%, 513 abs). Natalizumab chronically decreased CD8 subpopulations of $\mathrm{T}$ lymphocytes. Fingolimod reduced CD4+ but significantly increased \% of NK (49\%). Humoral immunity remained normal and unchanged during all that time. Deficit of NK cells in our patient could decreased resistance against brain tumour growth, as NK cells can play an important role in anti-tumour immunity [35]. Moreover, it is known that in MS, autoimmune conditions are mediated mostly by CD4+ T-cells with a proinflammatory Th1 and Th17 phenotype, causing inflammation and demyelinating lesions in the CNS [36]. The dominancy of glial tumours in MS leads to a hypothesis that chronic hyperactivation of glial cells via Th1/Th17 pathways could cause their neoplastic transformation in demyelinated lesions [34]. On the other hand, if MS-associated proinflammatory Type17 T-cells mediate potent antitumour immunity [34], suppression and sequestration of those cells could potentially cause its breakdown. We did not test our patient's Th17 lymphocytes, the mechanism could only be hypothesised. During natalizumab and fingolimod treatment we found lymphocytes decreased in periphery but we are not able to describe changes in the brain of our patient. This selective deficiency could have been involved in inefficient antitumour immune surveillance and tumour progression $[37,38]$.

Treatment by IMT could potentially trigger a variety of immunologic abnormalities that are typical for patients with malignant brain tumours [38, 39]. IMT may targeted many factors such as impaired responsiveness of peripheral blood lymphocytes to mitogens [39], failure of the $\mathrm{T}$ cells mediating adaptive immune responses within the local tumour micro-environment [40], and induction of regulatory T cells [41]. Development of GT can potentially be influenced by immunosuppressive cytokines (such as IL-10, TGF- $\beta$, and prostaglandin E2), and by down modulation of co-stimulatory molecules by antigen presenting cells (APCs) resulting in loss of T cell effector function [41]. Long-term monitoring of these markers in patients treated by highly effective IMT could be beneficial.

In tumour vessels, aggressive endothelial proliferation [42, 43], increases CD34+, a marker of endothelial progenitor cells [42]. Although natalizumab treatment results in an increase in CD34+ progenitor cells in both the bone marrow and the blood [44], it is not clear whether it can enhance tumour angiogenesis in a brain tumour. Moreover, increased angiogenesis was also described in PML lesions [11].

Indeed, the CNS biopsy remains the most useful method for defining the histological type of an atypical brain lesion susceptive of tumour. In our patient, Vimentin's over-expression in cancer correlates well with increased tumour growth, invasion and poor prognosis [45]. OLIG2 is highly expressed in all diffuse gliomas [46] and was found expressed in our patient's anaplastic astrocytoma samples. Tumourous cells were Nogo positive, Nogo-A exerts a growth inhibitory function leading to restricted axonal regeneration [47]. In our case Ki-67 was $\leq 5 \%$ but $>2 \%$. Worsened survival has been associated with Ki-67 > 2\% [48]. Mutation of IFH1 and positive p53 in our patient suggests secondary nature of the astrocytoma [49]. 

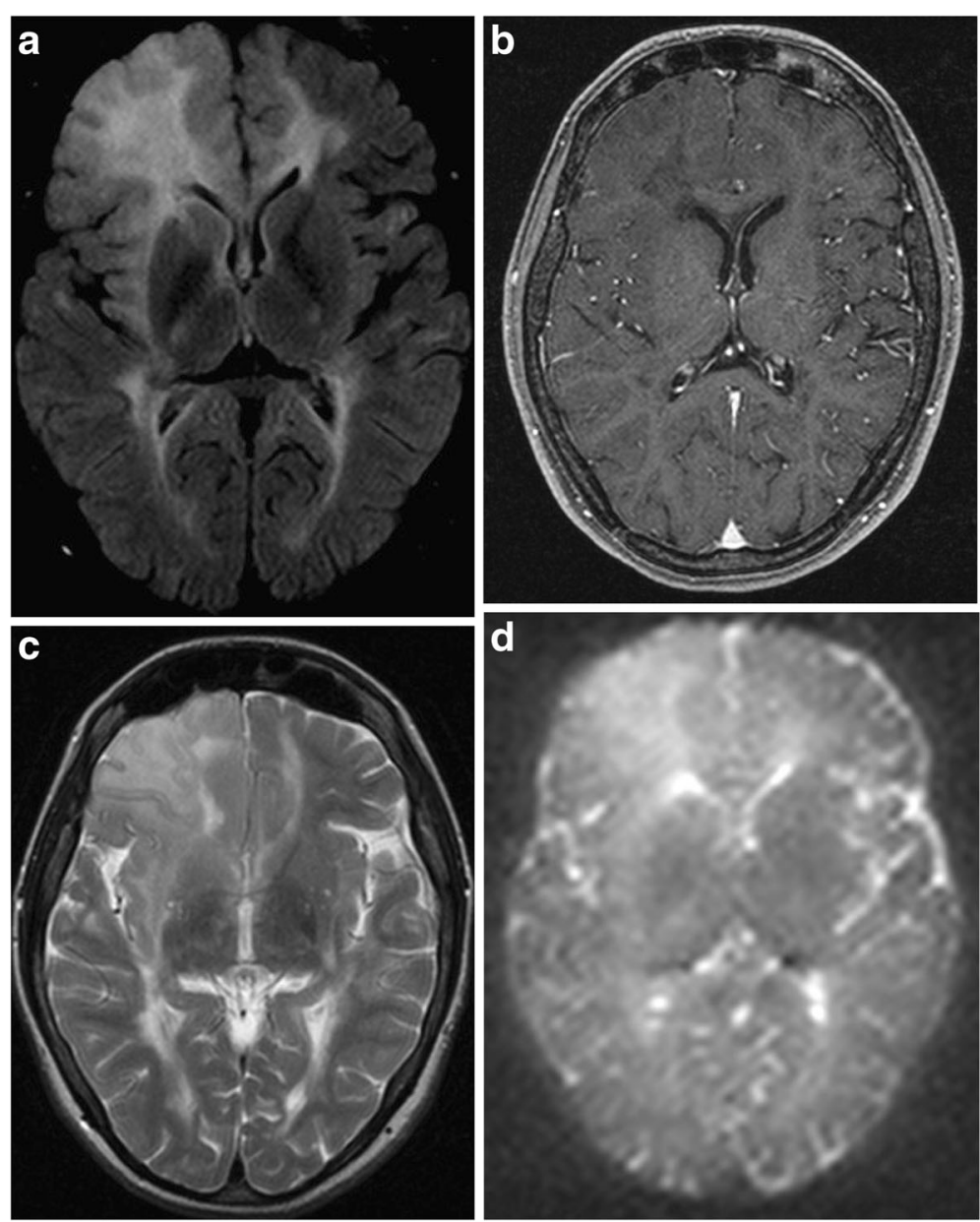

Fig. 3 a FLAIR, Fluid-Attenuated Inversion Recovery, transverse (2013): Progression of the non-homogeneously hyper-intensive demyelinated lesion of the right frontal lobe, involving U-fibers. The lesion is well-defined to cortex, confluent with white mater, and irregular in shape. $\mathbf{b}$ T1w, T1-weighted MRI, transverse (2013): Hypointense irregular lesion at the rim of the right corner of the lateral ventricle in the right frontal lobe and several slightly hypointensive areas subcortically with no post-Gad enhancement. c T2W, T2-weighted MRI, transverse (2013): Irregular signal intensity within the lesion in the right frontal lobe. d DWI, Diffusion Weighted Imaging (2013): High signal intensity in the right frontal cortico-subcortical region and slightly increased signal in periventricular regions of both hemispheres

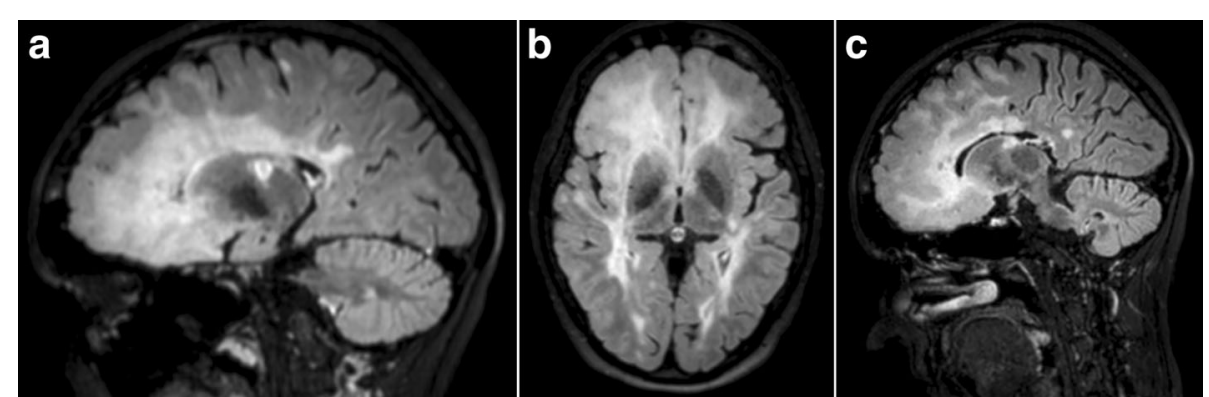

Fig. 4 a FLAIR, Fluid-Attenuated Inversion Recovery, sagittal (2014): Large non-homogenous hyperintense lesion of the right frontal lobe involving demyelination and oedema with mild mass-effect. It is relatively sharply defined to grey matter and confluent with white matter. Glial tumour is undetectable. b FLAIR, Fluid -Attenuated Inversion Recovery, transverse (2014): Diffuse hyperintense lesion of the right frontal lobe - demyelination. It has mild mass-effect. It is well-defined to cortex and to white matter and irregular in shape. c 3D DIR, 3D Double Inversion Recovery, sagittal (2014): Multifocal cortical involvement in the right frontal cortex adjacent to demyelinated lesions, diffuse confluent hyperintensive lesion in cortico-subcortical fronto-polar region 


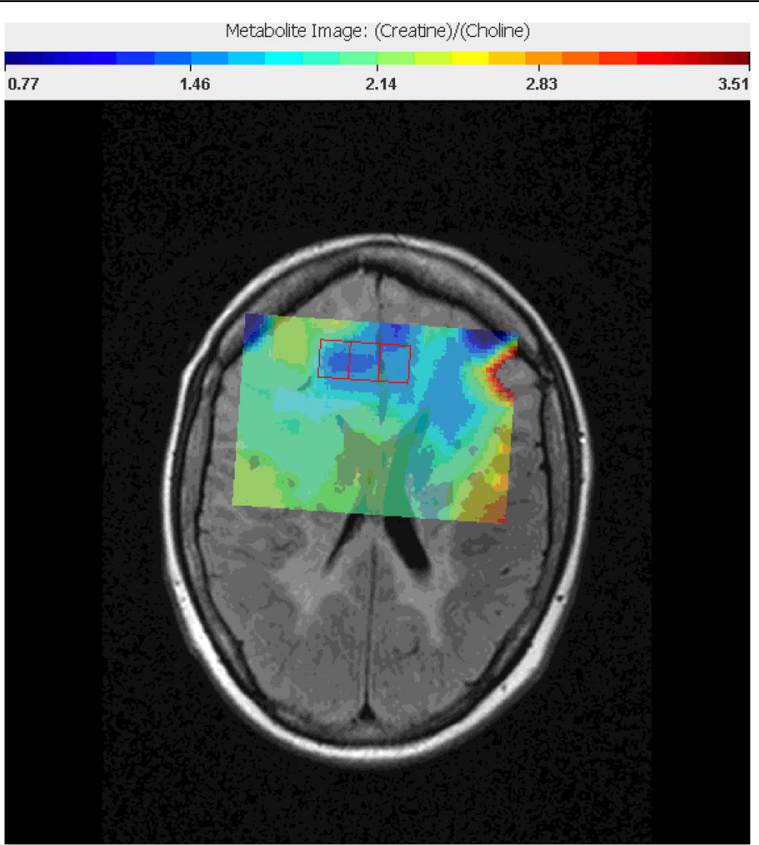

Fig. $5{ }^{1}$ HMRS, ${ }^{1} \mathrm{H}$-magnetic resonance spectroscopy (2015): $1 \mathrm{H}-\mathrm{MRS}$ of the right and left frontal lobes - Creatine to Cholin maps, the decreased ratio may indicate tumorous tissue (red-contoured squares)
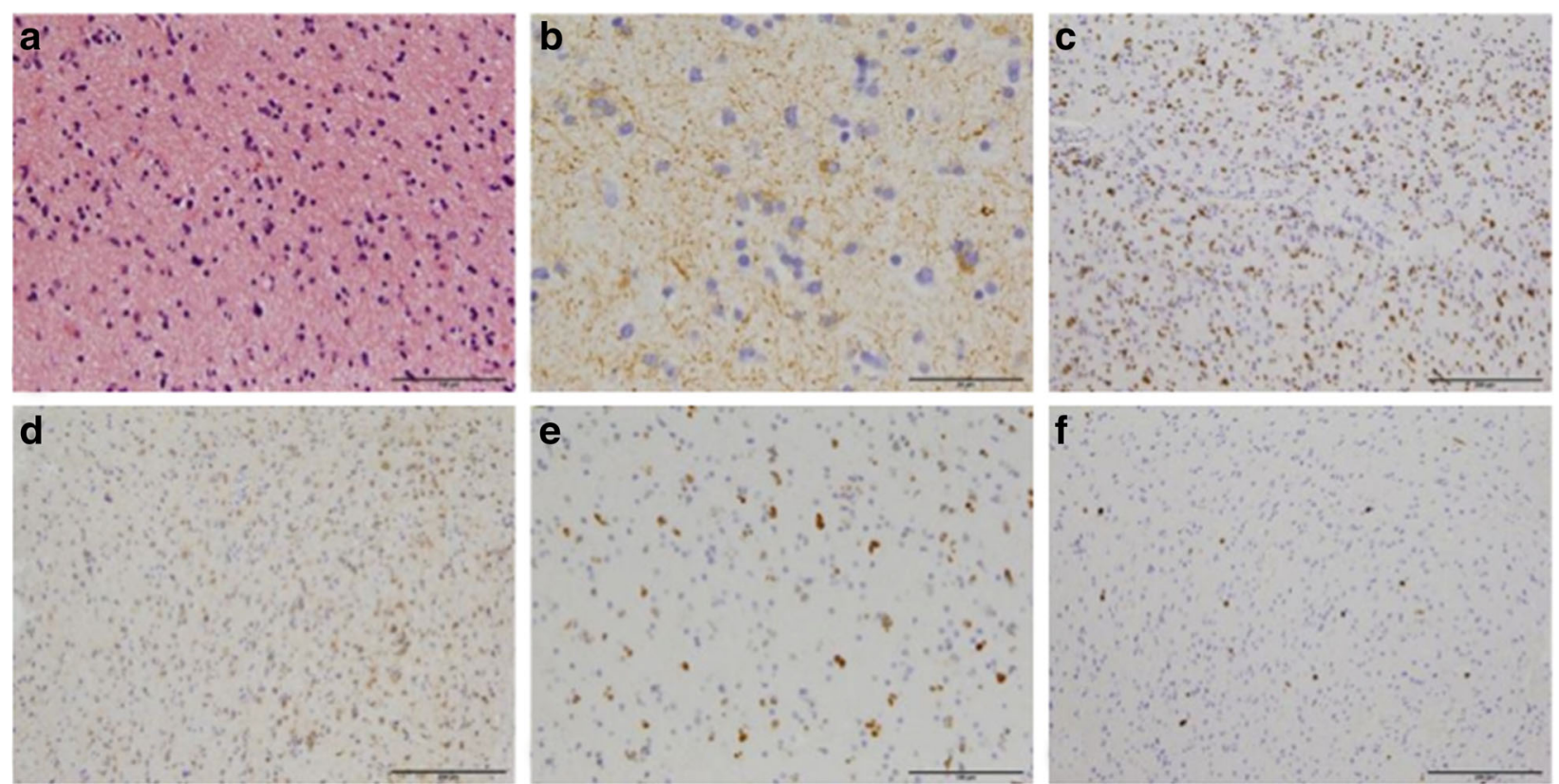

Fig. 6 Histopathology findings. (HE, LFB-PAS, Bielschowsky, CD3, SV40, Olig2, GFAP, Vimentin, Nogo-A, Ki67, IDH1, p53): a The hematoxylin-eosin (HE) staining revealed grey and white matter with a markedly increased cellularity. Cells appeared pleomorphic and demonstrated a diffuse invasion into the CNS tissue. The tumour cells were embedded into a glial matrix. The nuclei showed a pronounced variation with respect to size and shape and depicted an increased nucleolar prominence. Mitosis was detectable. Signs of necrosis or microvascular proliferation were absent. b The immunohistochemical staining for Glial Fibrillary Acidic Protein (GFAP). Vimentin marked the majority of the tumour cells. c Some of the tumour cells were positive for Olig2. The tumour cells were not positive for NogoA. The proliferation ranged between 2 and 3\% as determined by Ki67 immunohistochemistry. $\mathbf{d}$ The tumour cells were positive for isocitrate dehydrogenase1 (IDH1) and p53. e, f T-lymphocytes were not increased in the CD3 immunohistochemistry No SV40 positive cells were detected 


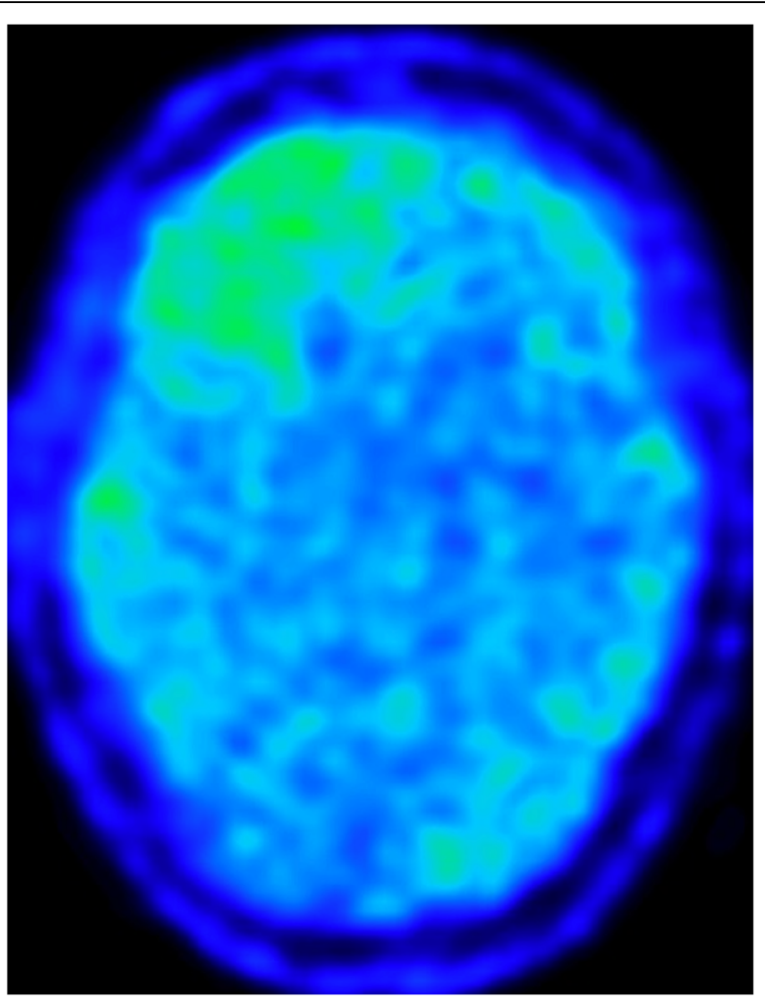

Fig. $7{ }^{11}$-MET PET, ${ }^{11}$ Methyl-Methionine Positron Emission Tomography (2015): Increased uptake of ${ }^{11} \mathrm{C}$-methionine in anaplastic astrocytoma in the right frontal cortico-subcortical region, showing high proliferation index of the tumour. Lower uptake was also detected in left frontal and occcipital cortical areas

In our patient we did not prove the histopathological triad of PML (multifocal demyelination, hyperchromatic, enlarged oligodendroglial nuclei, and enlarged bizarre astrocytes with lobulated hyperchromatic nuclei) [11, 27], which would have been a rather convincing evidence of the disorder. In Table 1, we summarise the differential diagnoses of tumefactive demyelinated lesions, malignant glial tumours, PML and PML associated with IRIS. We hypothesise that IMT may have transformed the glial cells into malignant GT. However, in a descriptive study among 22,563 French MS patients, including patients receiving IMT, brain tumours were not detected in total of 253 patients $(1.2 \%)$ with a history of cancer [45]. In the SENTINEL trial of natalizumab in combination with interferon beta-1a, the incidence rate of cancer in the combination group $(n=589)$ was $1 \%$ compared to $2 \%$ in the interferon beta-1a alone group $(n=582)$ [50]. In interim analysis of TOP study, including 4821 patients from 16 countries, the incidence of malignancies was $0.5 \%$. There were 24 patients with 12 types of malignancies. Glioblastoma was detected in 1 patient, while breast cancer was the most common, affecting seven patients (all female) [51].

Our patient was the carrier of human leukocyte antigens (HLA)-DRB 1*15 and DRB 1*11 alleles, and heterozygote of single nucleotide polymorphism rs3135388, which is typical for multiple sclerosis [52]. Although expression of HLA antigens is important for the immune response against infectious agents and malignant cells, there is an information gap about the link between HLA antigens and brain glial tumours. However, one prospective study, focused on HLA typing of German Caucasian patients, found that HLA-DRB1*15 in combination with HLADRB1*11 was associated with higher (a 13.4-fold increased) risk of glioma than was found for other HLA alone or in other combination [53]. It might explain the occurrence of astrocytoma Grade III in our patient.

We suppose that the anaplastic astrocytoma in our patient, developed after the diagnosis of MS, could have arisen in demyelinative plaques with reactive gliosis and could have evolved from a low grade glioma to anaplastic astrocytoma over time. The role of the immunomodulatory treatment as well as other immunological factors in malignant transformation of the tumour can only be hypothesised. The association between gliomas and MS is uncommon but it must be kept in mind when an atypical tumefactive lesion develops in a patient with MS. In our case, it is the first time when malignant glioma was misdiagnosed as PML. 


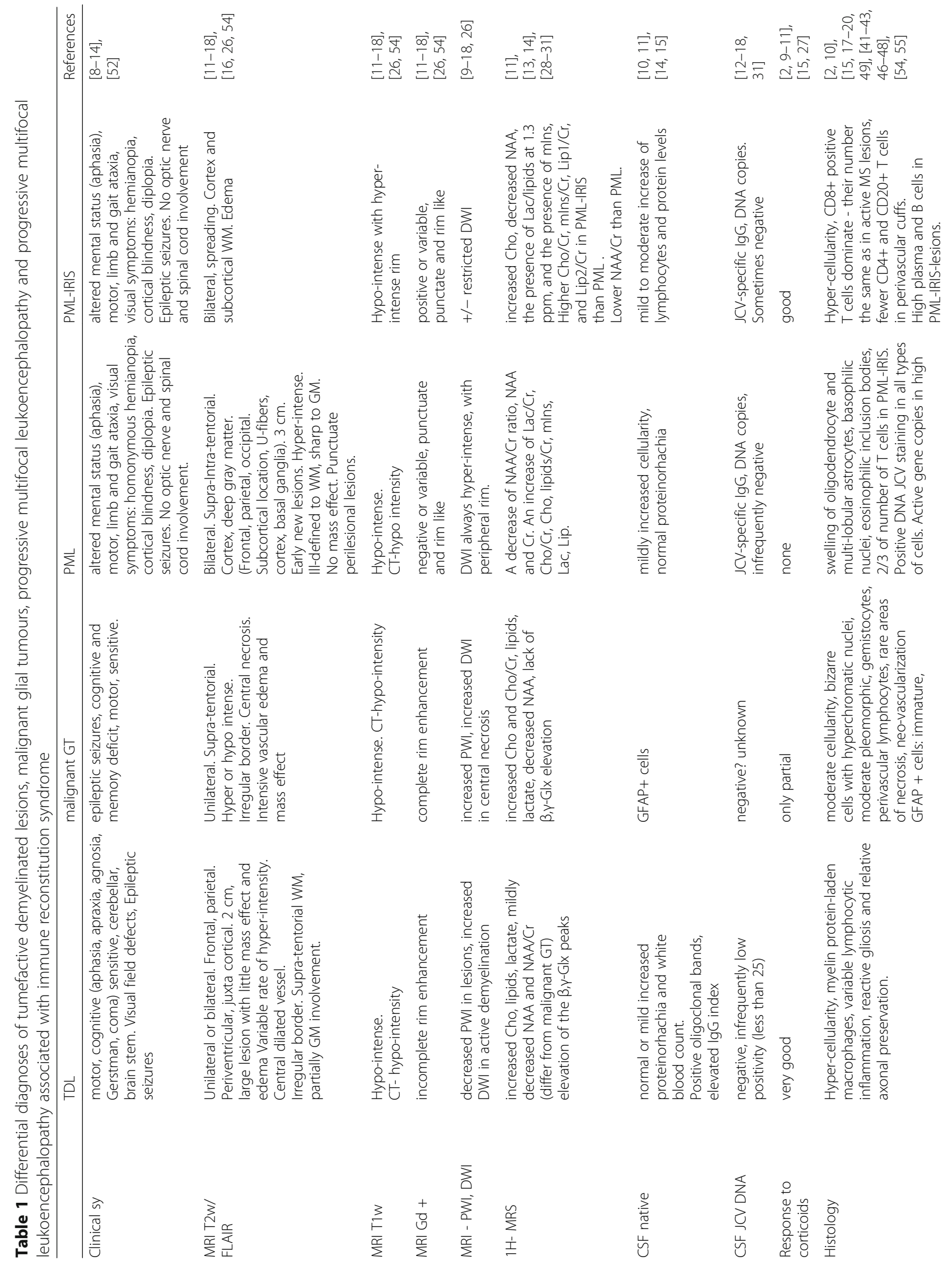




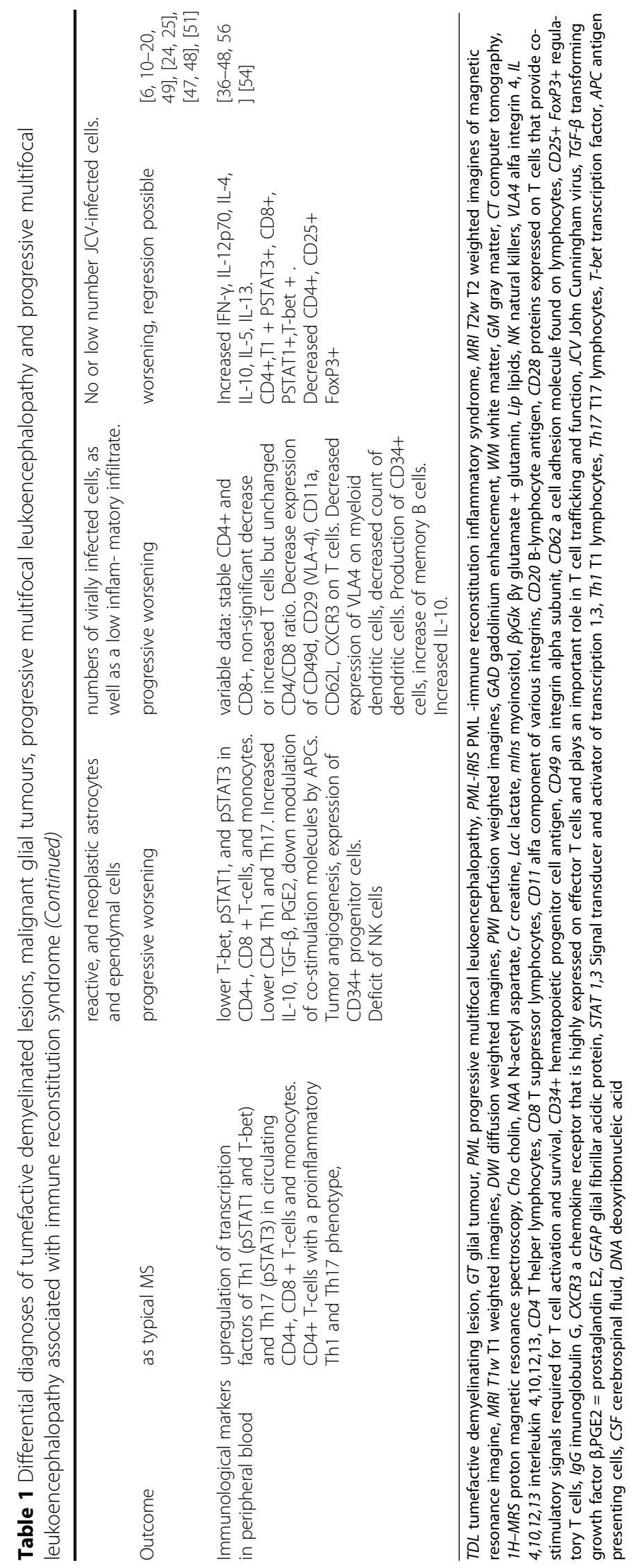




\begin{abstract}
Abbreviations
${ }^{11} \mathrm{C}-\mathrm{MET}$ PET: ${ }^{11}$ methyl-methionine positron emission tomography; ${ }^{1} \mathrm{H}$ MRS: ${ }^{1} \mathrm{H}$-proton MR spectroscopy; APC: Antigen Presenting Cell; CNS: Central Nervous System; CSF: Cerebrospinal Fluid; CT: Computer Tomography; DNA: Deoxyribonucleotid Acid; EDSS: Expanded Disability Status Scale; GFAP: Glial Fibrillary Acidic Protein; GT: Glial Tumour; HE: Hematoxylin and Eosin; HLA: Human Leukocyte Antigen; IDH: Isocitrate Dehydrogenase1; IL10: Interleukin-10; IMT: Immuno-modulatory Treatment; IRIS -: Immune Reconstitution Inflammatory Syndrome; JCV: John Cunningham virus; Ki-67: a nuclear protein that is associated with cellular proliferation; MRI -: Magnetic Resonance Imaging; MS: Multiple Sclerosis; Nogo-A: a high molecular weight transmembrane protein expressed by oligodendrocytes in white matter of the CNS; Olig2: Oligodendrocyte transcription factor; p53: cellular tumour antigen; PCR: Polymerase Chain Reaction; PML: Progressive Multifocal Leukoencephalopathy; SV40: Simian Virus 40; TDL: Tumefactive Demyelinating Lesion; TGF- $\beta$ : Transforming Growth Factor- $\beta$; VEP: Visual Evoked Potentials
\end{abstract}

\section{Acknowledgements}

The authors wish to thank Ms. Hana Jesenska who assisted in the proofreading of the manuscript.

\section{Funding}

The work has been supported in the data analysis and writing of the study by the Project VEGA 1/0287/16 and Grant APW 15/0107.

\section{Availability of data and materials}

The datasets used and analysed during the current study are available from the corresponding author on reasonable request.

\section{Authors' contributions}

EKa: manuscript writing, analysis and interpretation of data; JM: patient follow-up examination; WB:histopathological analysis; MB, PH, EB, SŠ, EKu: literature search, analysis and interpretation of data; KZ: analysis and interpretation of radiological tests; DČ: genetic analysis; All authors read and approved the final manuscript.

\section{Competing interests}

On behalf of all authors, the corresponding author states that there is no conflict of interest. The authors alone are responsible for the content and writing of the paper.

\section{Consent for publication}

Written informed consent was obtained from the next of kin of the patient for publication of this case report and accompanying images. A copy of the written consent is available for review by the editor of this journal.

\section{Ethics approval and consent to participate}

Ethics committee of Jessenius Faculty of Medicine at Comenius University (Slovakia) approved the study under number EK 1678/2015.

\section{Author details}

${ }^{1}$ Clinic of Neurology, Jessenius Faculty of Medicine, Comenius University in Bratislava, Kollárova 2, 03659 Martin, Slovak Republic. Department of Medical Biochemistry, Jessenius Faculty of Medicine, Comenius University in Bratislava, Kollárova 2, 03659 Martin, Slovak Republic. ${ }^{3}$ Clinic of Radiodiagnostics, Jessenius Faculty of Medicine, Comenius University in Bratislava, Kollárova 2, 03659 Martin, Slovak Republic. ${ }^{4}$ Institut für Neuropathologie Universitätsmedizin Göttingen, Robert-Koch-Str, 4037075 Göttingen, Germany.

Received: 7 July 2016 Accepted: 9 June 2017

Published online: 19 June 2017

\section{References}

1. Wiendl H, Toyka KV, Rieckmann P, Gold R, Hartung HP, Hohlfeld R. Basic and escalating immunomodulatory treatments in multiple sclerosis: current therapeutic recommendations. J Neurol. 2008;255:1449-63.

2. Currie $\mathrm{S}$, Urich H. Concurrence of multiple sclerosis and glioma. J Neuro Neurosurg Psychiatry. 1974;37:598-605.
3. Kalimo H, Frey H, Raine CS, Törmä T, Röyttä M. Late-onset malignant astrocytoma in a case of multiple sclerosis. Clinical, neuropathological, virological, and tissue culture studies. Acta Neuropathol. 1979;46:231-4.

4. Hofer $S$, Linnebank $M$, Weller $M$, et al. Cancer risk among patients with multiple sclerosis and their parents. Neurology. 2010;74:614-5.

5. Werneck LC, Scola RH, Arruda WO, Torres LF. Glioma and multiple sclerosis: case report. Arq Neuropsiquiatr. 2002 Jun;60:469-74.

6. Plantone D, Renna R, Sbardella E, Koudriavtseva T. Concurrence of multiple sclerosis and brain tumors. Front Neurol. 2015;6:40.

7. Hutchinson M. Safety first, efficacy second in disease modifying therapies. Mult Scler. 2011;17:380-1.

8. Sørensen PS, Bertolotto A, Edan G, et al. Risk stratification for progressive multifocal leukoencephalopathy in patients treated with natalizumab. Mult Scler. 2012;18:143-52.

9. Bloomgren G, Richman S, Hotermans C, et al. Risk of natalizumab-associated progressive multifocal leukoencephalopathy. N Engl J Med. 2012;366:1870-80.

10. Tan CS, Koralnik IJ. Progressive multifocal leukoencephalopathy and other disorders caused by JC virus: clinical features and pathogenesis. Lancet Neurol. 2010;9:425-37.

11. Berger JR, Aksamit AJ, Clifford DB, et al. PML diagnostic criteria: consensus statement from the AAN Neuroinfectious disease section. Neurology. 2013; 80:1430-8.

12. Wattjes MP, Richert ND, Killestein J, et al. The chameleon of neuroinflammation: magnetic resonance imaging characteristics of natalizumab-associated progressive multifocal leukoencephalopathy. Mult Scler. 2013;19:1826-40.

13. Shah R, Bag AK, Chapman PR, Cure JK. Imaging manifestations of progressive multifocal leucoencephalopathy. Clin Radiol. 2010;65:431-9.

14. Yamashita S, Kimura E, Hirano T, Uchino M. Tumefactive multiple sclerosis. Inter Med. 2009:48:1113-4

15. Lucchinetti CF, Gavrilova RH, Metz I, et al. Clinical and radiographic spectrum of pathologically confirmed tumefactive multiple sclerosis. Brain. 2008;131:1759-75

16. Given CA, Stevens BS, Lee C. The MRI appearance of tumefactive demyelinating lesions. AJR Am J Roentgenol. 2004;182:195-9.

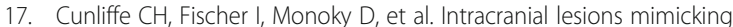
neoplasms. Arch Pathol Lab Med. 2009;133:101-23.

18. Huisman TAGM. Tumor-like lesions of the brain. Cancer Imaging. 2009:9:510-3.

19. Lee M, Walsh K, Rey-Dios R, Anderson M. Progressive multifocal leukoencephalopathy mimicking high grade glioma in an immunocompetent patient: a case report. Neuro Oncology. 2014;16:v149-50.

20. Burger PC, Vogel FS, Green SB, Strike TA. Glioblastoma multiforme and anaplastic astrocytoma. Pathologic criteria and prognostic implications. Cancer. 1985;56(5):1106-11.

21. Kingwell $E$, Bajdik C, Phillips $N$, et al. Cancer risk in multiple sclerosis: findings from British Columbia. Canada Brain. 2012;135:2973-9.

22. Fois $A F$, Wotton $C J$, Yeates $D$, et al. Cancer in patients with motor neuron disease, multiple sclerosis and Parkinson's disease: record linkage studies. Neurol Neurosurg Psychiatry. 2010;81:215-21.

23. Handel AE, Ramagopalan SV. Multiple sclerosis and risk of cancer: a metaanalysis. J Neurol Neurosurg Psychiatry. 2010;81:1413-4.

24. Catala-Lopez F, Suarez-Pinilla M, Suarez-Pinilla P, et al. Inverse and direct cancer comorbidity in people with central nervous system disorders: a meta-analysis of cancer incidence in 577,013 participants of 50 observational studies. Psychother Psychosom. 2014:83:89-105.

25. Hemminki K, Liu X, Försti A, Ji J, Sundquist J, Sundquist K. Subsequent brain tumors in patients with autoimmune disease. Neuro-Oncology. 2013:15:1142-50.

26. Kim DS, Na DG, Kim KH, Kim J, Kim E, Yun BL, et al. Distinguishing tumefactive demyelinating lesions from glioma or central nervous system lymphoma: added value of unenhanced CT compared with conventional contrast-enhanced MR inaging. Radiology. 2009;251:467-75.

27. Kuhle J, Gosert R, Bühler R, et al. Management and outcome of CSF-JC virus PCRnegative PML in a natalizumab-treated patient with MS. Neurology. 2011;77:2010-6.

28. Cuvinciuc V, Martin-Blondel G, Marchou B. Bonneville F proton MR spectroscopy of progressive multifocal leukoencephalopathy-immune reconstitution inflammatory syndrome. Am J Neuroradiol. 2010;31:E69-70.

29. Cianfoni AS, Niku SG. Imbesi SG. Metabolite findings in tumefactive demyelinating lesions utilizing short echo time proton magnetic resonance spectroscopy. Am J Neuroradiol 2007; 28:272-277.

30. Howe FA, Opstad KS ${ }^{1} \mathrm{H}$ MR spectroscopy of brain tumours and masses. NMR Biomed. 2003;16:123-31. 
31. De Stefano N, Caramanos Z, Preul MC, Francis G, Antel JP, Arnold DL. In vivo differentiation of astrocytic brain tumors and isolated demyelinating lesions of the type seen in multiple sclerosis using $1 \mathrm{H}$ magnetic resonance spectroscopic imaging. Ann Neurol. 1998:44:273-8.

32. Chung J-K, Kim Y, Kim S, et al. Usefulness of 11C-methionine PET in the evaluation of brain lesions that are hypo or isometabolic on 18F-FDG PET. Eur J Nucl Med Mol Imagine. 2002;29:176-82.

33. Horakova D, Kalincik T. Blahova-Dusankova et al. Clinical correlates of grey matter pathology in multiple sclerosis BMC Neurology. 2012;12:10.

34. Weiner HL. The challenge of multiple sclerosis: how do we cure a chronic heterogeneous disease? Ann Neurol. 2009;65:239-48.

35. Kmiecik J, Zimmer J. Chekenya M. Natural killer cells in intracranial neoplasms: presence and therapeutic efficacy against brain tumours J Neuro-Oncol. 2013;116:1-9.

36. Okada H, Khoury SJ. Type17 T-cells in central nervous system autoimmunity and tumors. J Clin Immunol. 2012;32:802-8.

37. Kmiecik J, Poli A, Brons NH, Waha A, Eide GE, Enger P $\varnothing$, et al. Elevated CD3+ and CD8+ tumor-infiltrating immune cells correlate with prolonged survival in glioblastoma patients despite integrated immunosuppressive mechanisms in the tumor microenvironment and at the systemic level. J Neuroimmun. 2013;264:71-83.

38. Perrin G, Schnuriger V, Quiquerez AL, Saas P, Pannetier C, de Tribolet N, et al. Astrocytoma infiltrating lymphocytes include major T cell clonal expansions confined to the CD8 subset. Int Immunol. 1999;11:1337-50.

39. Elliott LH, Brooks WH, Roszman TL. Cytokinetic basis for the impaired activation of lymphocytes from patients with primary intracranial tumors. J Immunol. 1984;132:1208-15.

40. Fontana A, Hengartner H, de Tribolet N, Weber E. Glioblastoma cells release interleukin 1 and factors inhibiting interleukin 2-mediated effects. J Immunol. 1984;132:1837-44.

41. Wei J, Barr J, Kong LY, Wang Y, Wu A, Sharma AK, et al. Glioblastoma cancer-initiating cells inhibit T-cell proliferation and effector responses by the signal transducers and activators of transcription 3 pathway. Mol Cancer Ther. 2010;9:67-78.

42. Soda Y, Marumoto T, Friedmann-Morvinski D, Soda M, Liu F, Michiue H, et al. Transdifferentiation of glioblastoma cells into vascular endothelial cells. Proc Natl Acad Sci U S A. 2011;15(108):4274-80.

43. Jain RK, di Tomaso E, Duda DG, et al. Angiogenesis in brain tumours. Nat Rev Neurosci. 2007:8:610-22.

44. Jin H, Aiyer A, Su J, Borgstrom P, Stupack D, Friedlander M, et al. A homing mechanism for bone marrow-derived progenitor cell recruitment to the neovasculature. J Clin Invest. 2006;116:652-62.

45. Satelli A, Li S. Vimentin as a potential molecular target in cancer therapy or Vimentin, an overview and its potential as a molecular target for cancer therapy. Cell Mol Life Sci. 2011;68:3033-46.

46. Ligon $\mathrm{KL}$, Alberta JA, Kho AT, Weiss J, Kwaan MR, Nutt $\mathrm{CL}$, et al. The oligodendroglial lineage marker OLIG2 is universally expressed in diffuse gliomas. J Neuropathol Exp Neurol. 2004;63:499-509.

47. Schwab EM. Functions of Nogo proteins and their receptors in the nervous system. Nat Rev Neurosci. 2010;11:799-811.

48. Fisher BJ, Naumova E, Leighton CC, Naumov GN, Kerklviet N, Fortin D, et al. Ki-67: a prognostic factor for low-grade glioma? Int J Radiat Oncol Biol Phys. 2002;52:996-1001.

49. Khalil A, Serracino H, Damek DM, Ney D, Lillehei KO, Kleinschmidt-DeMasters BK. Genetic characterization of gliomas arising in patients with multiple sclerosis. J Neuro-Oncol. 2012;109:261-72.

50. Rudick RA, Stuart WH, Calabresi PA, et al. Natalizumab plus interferon beta1a for relapsing multiple sclerosis. N Engl J Med. 2006;354:911-23.

51. Butzkueven $H$, Kappos L, Pellegrini F, Trojano M, Wiendl H, Patel RN, et al. Belachew S; TYSABRI observational program (TOP) investigators. Efficacy and safety of natalizumab in multiple sclerosis: interim observational programme results. J Neurol Neurosurg Psychiatry. 2014;85:1190-7.

52. International Multiple Sclerosis Genetics Consortium., Hafler DA, Compston A, Sawcer S, Lander ES, Daly MJ, De Jager PL, de Bakker PI, Gabriel SB, Mirel DB, Ivinson AJ, Pericak-Vance MA, Gregory SG, Rioux JD, McCauley JL, Haines JL, Barcellos LF, Cree B, Oksenberg JR, Hauser SL. Risk alleles for multiple sclerosis identified by a genomewide study. N Engl J Med. 2007 Aug 30;357:851-62.

53. Machulla HK, Steinborn F, Schaaf A, Heidecke V, Rainov NG. Brain glioma and human leukocyte antigens (HLA)-is there an association? J NeuroOncol. 2001;52:253-61.
54. Frisullo G, Patanella AK, Nociti V, Cianfoni A, lorio R, Bianco A, et al. Glioblastoma in multiple sclerosis: a case report. J Neuro-Oncol. 2009;94:141-4.

55. Metz I, Radue E-W, Oterino A, et al. Pathology of immune reconstitution inflammatory syndrome in multiple sclerosis with natalizumab-associated progressive multifocal leukoencephalopathy. Acta Neuropathol. 2012;123:235-45.

56. Lebrun C, Vermersch P, Brassat D, et al. Cancer and multiple sclerosis in the era of disease-modifying treatments. J Neurol. 2011;258:1304-11.

\section{Submit your next manuscript to BioMed Central and we will help you at every step:}

- We accept pre-submission inquiries

- Our selector tool helps you to find the most relevant journal

- We provide round the clock customer support

- Convenient online submission

- Thorough peer review

- Inclusion in PubMed and all major indexing services

- Maximum visibility for your research

Submit your manuscript at www.biomedcentral.com/submit
Biomed Central 